\title{
Electrophysiological studies in alcoholism
}

\author{
EILEEN BLACKSTOCK, GEOFFREY RUSHWORTH, AND DENNIS GATH \\ From the Unit of Clinical Neurophysiology, Department of Neurology, Churchill Hospital, Oxford, \\ and the University Department of Psychiatry, Warneford Hospital, Oxford
}

SUMMARY Using a range of electrophysiological techniques, it has been possible to demonstrate impaired function in smaller calibre motor fibres and in distal large cutaneous sensory nerve fibres in both alcoholic patients without neuropathy and in those alcoholics with clinical manifestations of peripheral nerve disease. Evidence of more proximal involvement of Ia sensory fibres was obtained, but in the majority of our patients, large motor fibres functioned normally. The nature of the underlying pathological process is discussed.

The study of the disorders of peripheral nerve function has been greatly facilitated by the development and application of refined electrophysiological techniques. Recent advances in this field, such as the introduction by Hopf $(1962,1963)$ of a method by which velocity in the slower conducting, and hence, fine motor nerve fibres can be measured, together with the development by Buchthal and Rosenfalck (1966) of a detailed technique for measuring cutaneous sensory nerve potentials and their maximum velocities, have widened the scope of electrophysiological procedures.

Some workers (Mawdsley and Mayer, 1965; Juul-Jensen and Mayer, 1966), using the now well-established methods of measuring maximum conduction velocities in peripheral motor and sensory nerve fibres in alcoholic patients with polyneuropathy, have found small decreases in these velocities. However, Perfetti, Milone, and Pacchiani (1967), using Hopf's method of double stimulation to examine the ulnar nerve in alcoholics with polyneuropathy or other neurological disturbances, found that the large motor fibres conducted normally, whereas slowing of velocity was observed in the small fibres.

Similarly equivocal findings have been reported following electrophysiological investigation of alcoholic patients who at that stage had no clinical evidence of peripheral nerve disturbance. Several workers (Jurko, Currier, and Foshee, 1964; Mawdsley and Mayer, 1965; Bergamini, Gandiglio, Fra, Bergamasco, Bram, and Mombelli, 1965; Wanamaker and Skillman, 1966) have reported marginal reductions in maximum conduction velocities in peripheral motor nerves in such patients, whereas others (Juul-Jensen and Mayer, 1966; Vacek, Štika, Grófová, and Warman, 1969) have found maximum conduction velocities in these nerve fibres to be withino normal limits. Lack of agreement also exist? between those who have studied nerve conduc tion in the peripheral sensory nerve fibres i⿱乛龰 these patients. Mawdsley and Mayer (1965 $\vec{F}$ indicated that electrophysiological abnormali $\varnothing$ ties occurred equally in peripheral sensory ans motor nerve fibres, whereas Bergamini et at혹을 (1965), studying a small group of alcoholics; concluded that significantly greater electrophysiological abnormalities were detectable in peripheral sensory fibres.

It seemed worthwhile to investigate, using a range of electrophysiological techniques, both alcoholics with peripheral nerve lesions and those with no manifestations of alcoholic polyneuropathy, in order to determine whether or not electrophysiological abnormalities of motor and sensory nerve fibres were detectable. We were particularly interested in the measurement of cutaneous sensory nerve potentials and their maximum velocities in these patients, as we felt that useful information about distal sensory nerve function may be obtained by the application of this technique.

\section{PATIENTS}

The patients studied had been admitted to local $N$ psychiatric hospitals (the Warneford Hospital, a N small acute psychiatric hospital, and the Ley Clinic, a unit specializing in the treatment of drug dependency) for treatment of alcoholism or its attendant 
TABLE 1

CLINICAL DETAILS

\begin{tabular}{|c|c|c|c|c|c|c|c|}
\hline \multirow{2}{*}{$\begin{array}{l}\text { Patient } \\
\text { No. }\end{array}$} & \multirow{2}{*}{$\begin{array}{l}\text { Age } \\
(y r)\end{array}$} & \multicolumn{4}{|c|}{ Physical findings } & \multirow{2}{*}{$\begin{array}{l}\text { Dietary } \\
\text { Neglect }\end{array}$} & \multirow{2}{*}{$\begin{array}{l}\text { Mental state on } \\
\text { admission }\end{array}$} \\
\hline & & $\begin{array}{l}\text { Muscle power and } \\
\text { coordination }\end{array}$ & Sensibility & Reflexes & $\begin{array}{l}\text { Other } \\
\text { findings }\end{array}$ & & \\
\hline 1 & 35 & $\begin{array}{l}\text { Marked proximal and } \\
\text { distal muscle wasting } \\
\text { with loss of power in } \\
\text { arms and legs. Inco- } \\
\text { ordination in arms and } \\
\text { legs }\end{array}$ & $\begin{array}{l}\text { Defective appreciation, } \\
\text { light touch, pin prick, } \\
\text { vibration, and position } \\
\text { sense in arms and legs }\end{array}$ & $\begin{array}{l}\text { Absent } \\
\text { knee } \\
\text { and } \\
\text { ankle } \\
\text { jerks }\end{array}$ & $\begin{array}{l}\text { Hepatic } \\
\text { enlargement }\end{array}$ & +++ & $\begin{array}{l}\text { Disorientation for time, } \\
\text { place, and person. } \\
\text { Emotionally labile. Im- } \\
\text { paired memory for recent } \\
\text { events. Short-term } \\
\text { memory impaired }\end{array}$ \\
\hline 2 & 63 & $\begin{array}{l}\text { Moderate proximal and } \\
\text { distal muscle wasting in } \\
\text { legs. Power and co- } \\
\text { ordination normal }\end{array}$ & $\begin{array}{l}\text { Defective appreciation } \\
\text { light touch, pin prick, } \\
\text { and vibration sense } \\
\text { below the knee }\end{array}$ & $\begin{array}{l}\text { Absent } \\
\text { knee } \\
\text { and } \\
\text { ankle } \\
\text { jerks }\end{array}$ & $\begin{array}{l}\text { Hepatic } \\
\text { enlargement }\end{array}$ & +++ & $\begin{array}{l}\text { Disorientation for time, } \\
\text { place, and person. Gross } \\
\text { memory impairment for } \\
\text { recent and remote events }\end{array}$ \\
\hline 3 & 50 & Normal & $\begin{array}{l}\text { Defective appreciation } \\
\text { pin prick and vibration } \\
\text { sense below knee }\end{array}$ & Normal & $\begin{array}{l}\text { Hepatic } \\
\text { enlargement }\end{array}$ & +++ & Normal \\
\hline 4 & 55 & Normal & $\begin{array}{l}\text { Defective appreciation } \\
\text { light touch and pin prick } \\
\text { distally in arms and legs. } \\
\text { Absent vibration sense } \\
\text { lower limbs }\end{array}$ & $\begin{array}{l}\text { Absent } \\
\text { ankle } \\
\text { jerks }\end{array}$ & $\begin{array}{l}\text { Hepatic } \\
\text { enlargement }\end{array}$ & ++ & Normal \\
\hline 5 & 55 & $\begin{array}{l}\text { Slight wasting proximal } \\
\text { and distal muscles in } \\
\text { legs. Power and co- } \\
\text { ordination normal }\end{array}$ & $\begin{array}{l}\text { Defective appreciation of } \\
\text { light touch and pin } \\
\text { prick distally in arms } \\
\text { and legs }\end{array}$ & $\begin{array}{l}\text { Absent } \\
\text { ankle } \\
\text { jerk }\end{array}$ & Nil & + & $\begin{array}{l}\text { Disorientation for time, } \\
\text { place, and person. Visual } \\
\text { hallucinations }\end{array}$ \\
\hline 6 & 50 & Normal & Normal & $\begin{array}{l}\text { Absent } \\
\text { ankle } \\
\text { jerk }\end{array}$ & $\begin{array}{l}\text { Hepatic } \\
\text { enlargement }\end{array}$ & +++ & $\begin{array}{l}\text { Impaired memory for } \\
\text { recent events. Impaired } \\
\text { short term memory }\end{array}$ \\
\hline
\end{tabular}

+ During month preceding admission one cooked meal daily. Snacks only at most other mealtimes.

++ During month preceding admission no cooked meals on most days.

+++ During month preceding admission no cooked meals on most days with loss of weight exceeding $14 \mathrm{lb}$.

complications. Selection of patients took place in so far as only patients who had at least one index of severe alcoholism - that is, early morning tremulousness relieved by further drinking, an abnormal pattern and frequency of drinking, alcohol amnesias, loss of control, and hallucinatory experiences-were admitted to the study. A single patient only showed just one of these features. Also, patients who had concurrent diseases like diabetes, or other possible causes of peripheral nerve disease, were excluded.

After admission, a history, including details of recent drinking and dietary habits, was taken from each patient, using a semistructured interview schedule. This was supplemented where possible by information obtained from relatives. A complete psychiatric and physical assessment was carried out on each patient.

Altogether 30 patients ( 23 males and seven females) were studied. The mean age of the group was 44.8 years (age range 21 to 65 years). The average age of commencing regular drinking was 20 years (range 13 to 37 years). More than half the patients (17) drank spirits (whisky, brandy, gin) exclusively; of the remainder, five drank sherry or cheap wine, two preferred beer or cider, and six patients were intermittent or regular methyl alcohol drinkers. Eight patients gave a history of severe dietary neglect with weight loss greater than $14 \mathrm{lb}(6.4 \mathrm{~kg})$ before hospitalization. On physical examination eight patients had hepatic enlargement; signs of peripheral nerve involvement, details of which are given in Table 1, were present in six patients (group I); the remaining 24 patients (group II) had no symptoms or signs of polyneuropathy.

As part of another study, measurement of thiamine deficiency (using the pyruvate tolerance test and the red cell transketolase estimation) was made in 13 patients, three of whom had neuropathy. These tests were carried out as soon as possible after hospitalization and before vitamin therapy was commenced. Abnormal pyruvate tolerance tests were present in four patients, one of whom had neuropathy, and in one of these four the red cell transketolase was also abnormal.

\section{METHODS}

All the tests were carried out in a warm room with 
the patient lying on a couch and covered with blankets. All patients were asked to warm up their arms by immersion in hot water for 10 minutes before the session. In all cases measurements were made on the non-dominant side. The limbs on which the tests were carried out were supported on hot water bottles throughout the procedure. The skin temperature of the distal part of the limbs was measured at the end of the recording session, the mean temperature being $33^{\circ} \mathrm{C}$.

1. MEASUREMENT OF MOTOR NERVE MAXIMUM CONDUCTION VELOCITIES Using coaxial needle electrodes, muscle action potentials were elicited from the abductor pollicis brevis after maximum electrical stimulation of the median nerve at the wrist, elbow, and in the axilla, and from the extensor digitorum brevis by stimulating the anterior tibial nerve at the ankle and the lateral popliteal nerve at the knee. The surface stimulating electrodes were of the Disa type, bipolar and approximately $5 \mathrm{~mm}$ in diameter, with an interelectrode distance of $25 \mathrm{~mm}$. Before stimulation at each site the skin was prepared by gentle sandpapering and application of electrode jelly. Square wave stimuli, derived from a Disa Multistim, were applied and repeated at the rate of one every $2 \mathrm{sec}$. The muscle action potentials were fed into a high input impedance cathode follower, amplified by conventional means and displayed on a double beam oscilloscope, one beam of which was fed with a time scale derived from a crystal oscillator (Digitimer, Devices Instruments Ltd). The muscle action potentials were simultaneously photographed as sweeps (speed $2 \mathrm{~mm} / \mathrm{msec}$ ). Latencies were measured from the stimulus artefact to the beginning of the initial deflection from the baseline of the compound potential. Distances between the various points of stimulation and the recording sites were measured along the course of the nerves and divided by appropriate latencies to give velocities.

2. MEASUREMENT OF CUTANEOUS SENSORY NERVE POTENTIALS The digital nerves were electrically stimulated using two silver rings $4 \mathrm{~mm}$ wide, covered by lint moistened with saline, and applied firmly around each finger in turn, with the cathode proximal to the first interphalangeal joint and the anode over the terminal interphalangeal joint. The surface recording electrodes, which consisted of silver probes contained in suction cups, with an interelectrode distance of $2 \mathrm{~cm}$, were placed exactly over the course at the wrist of the median and ulnar nerves in turn, these points having been accurately mapped out when recording the muscle action potentials. Square wave stimuli were applied and repeated at the rate of $2 / \mathrm{sec}$. The stimulus strength was adjusted to be supramaximal for the response. The sensory nerve action potentials were amplified and displayed on a double beam oscilloscope, as described above. The sensory potentials were simultaneously photographed as 10 superimposed sweeps (speed $5 \mathrm{~mm} / \mathrm{msec}$ ) on continuously moving $70 \mathrm{~mm}$ photographic paper. The latency of the nerve action potential was measured from the stimulus artefact to the beginning of the first positive deflection. Sensory nerve velocities were calculated by dividing the distance, measured on the skin, between the stimulating cathode and the recording site, by the appropriate latency.

3. MEASUREMENT OF H-REFLEX AND ANKLE JERK The $\mathrm{H}$-reflex was recorded from the soleus and gastro-
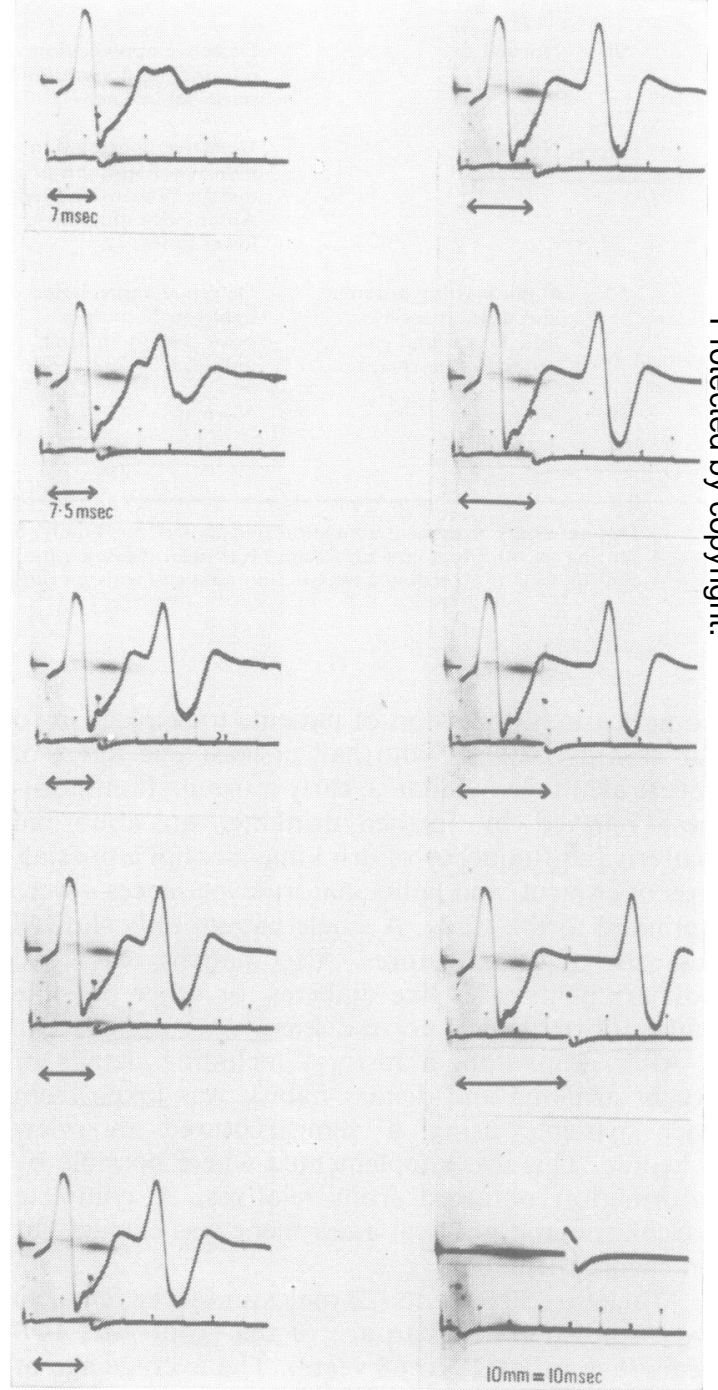

FIG. 1. Measurement of minimum motor conduction velocity using two supramaximal stimuli separated by successively greater time intervals. 


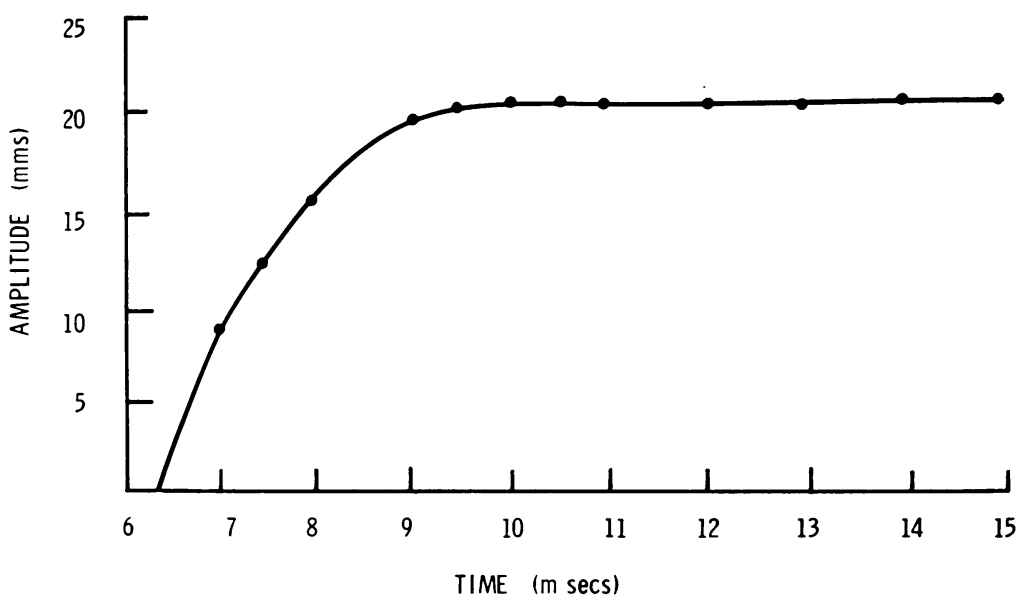

FIG. 2. Determination of the latency of the slow motor fibres.
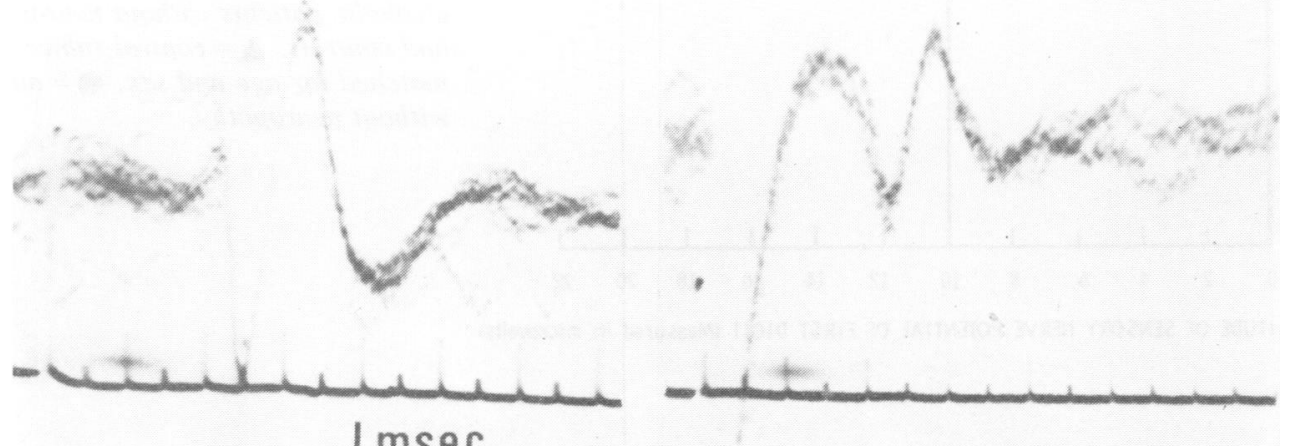

\section{$5 \mu \mathrm{v}$}
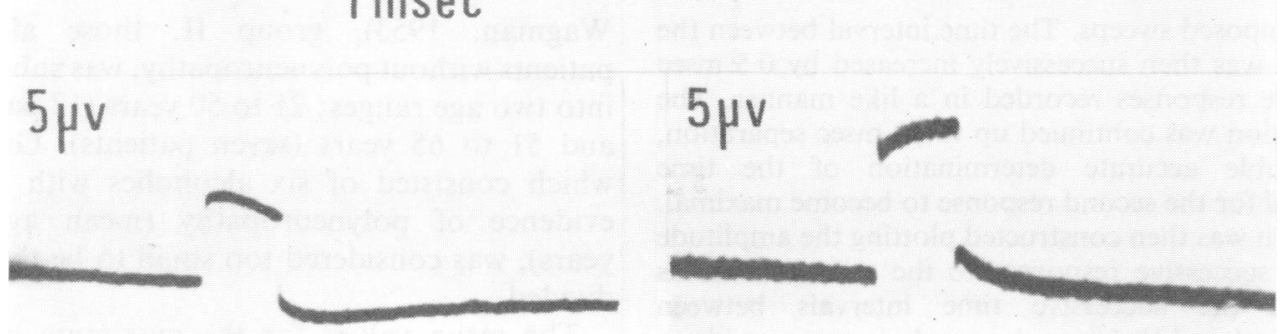

FIG. 3. Cutaneous sensory nerve potential (digit 1) of a healthy control subject compared with that of an alcoholic patient without neuropathy.

cnemius muscles by means of coaxial needle electrodes, after a submaximal stimulus had been applied to the medial popliteal nerve in the popliteal fossa. For the measurement of the latency of the ankle jerk, a patella hammer containing a piezoelectric crystal was used. This, when struck, produced a potential change capable of triggering the cathode ray oscilloscope. The reflex electrical activity of the calf muscles was recorded through needle electrodes as before.

4. MEASUREMENT OF MINIMUM MOTOR CONDUCTION VELOCITIES IN ULNAR NERVE This procedure was carried out on eight patients from group II. Hopf's method of double stimulation was used. Muscle action potentials were recorded from the abductor 
digiti minimi using surface electrodes, one over the muscle belly and the other over the tendinous insertion. Stimuli were delivered through two sets of bipolar stimulating electrodes which were strapped firmly to the arm, one over the course of the ulnar nerve at the wrist and the other above the elbow. The electrodes were also held throughout the procedure to prevent them slipping. Both stimuli were adjusted to give supramaximal responses separately. The separation in time was found at which the response to the second stimulus was just visible. This was recorded by photographing five minimum motor conduction velocity in the ulnar nerve was carried out on eight control subjects who were matched as closely as possible for age with group II alcoholics on whom this measurement was made.

\section{RESULTS}

MAXIMUM MOTOR CONDUCTION VELOCITIES As it is recognized that maximum conduction velocities in peripheral nerves may be slower in people over the age of 50 years (Norris, Shock, and

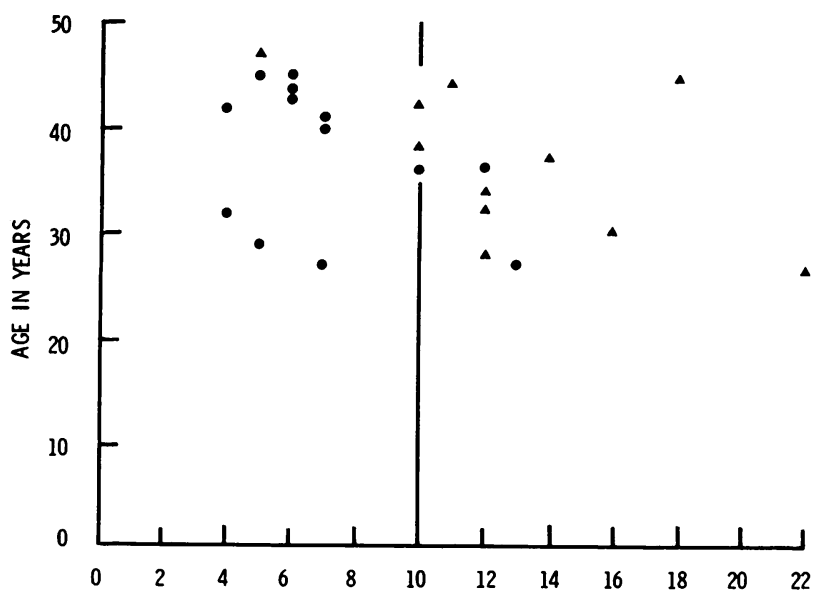

FIG. 4. Distribution of the amplitude of cutaneous sensory nerve potentials in alcoholic patients without neuropathy and controls. $\mathbf{\Delta}=$ control subject matched for age and sex. $=$ alcoholic without neuropathy.

AMPLITUDE OF SENSORY NERVE POTENTIAL OF FIRST DIGIT (Measured in microvolts)

superimposed sweeps. The time interval between the stimuli was then successively increased by $0.5 \mathrm{msec}$ and the responses recorded in a like manner. The separation was continued up to $20 \mathrm{msec}$ separation, to enable accurate determination of the time interval for the second response to become maximal. A graph was then constructed plotting the amplitude of the successive responses to the second stimulus against the successive time intervals between stimulus I and II. Using the graph, it was possible to determine the exact time interval at which the second response became maximal; this represented the latency of the slow motor fibres. The distance between the two stimulating cathodes was measured on the skin and the velocity calculated in the usual way.

5. CONTROL GROUP This consisted of 14 people drawn from the medical and nursing staff. Measurements of cutaneous sensory nerve potentials and their maximum conduction velocities, and the latencies of the H-reflex and the ankle jerk were made on each control subject. Measurement of the
Wagman, 1953), group II, those alcoholic patients without polyneuropathy, was subdivided into two age ranges: 21 to 50 years (17 patients), and 51 to 65 years (seven patients). Group I, which consisted of six alcoholics with clinical evidence of polyneuropathy (mean age 51.3 years), was considered too small to be thus subdivided.

The mean values for the maximum conduction velocities of the median and lateral popliteal nerves for group I patients are presented in Table 2.

These mean values are within the limits which are regarded as being normal in this laboratory for the segments of each nerve examined. Two patients in this group deserve closer attention however. Case 1, aged just 35 years, showed consistently low maximum conduction velocities in the upper limb for someone of this age (axilla-elbow segment $47 \mathrm{~m} / \mathrm{sec}$, elbow-wrist segment $46 \mathrm{~m} / \mathrm{sec}$ ). This patient also had the 
TABLE 2

MAXIMUM MOTOR CONDUCTION VELOCITIES IN ALCOHOLIC PATIENTS WITH POLYNEUROPATHY (GROUP I)

\begin{tabular}{lcc}
\hline Nerve & Mean $( \pm$ one $S D)$ & Range \\
\hline Median & & \\
Axilla-elbow & $61 \cdot 3 \pm 10 \cdot 3$ & $47-80$ \\
Elbow-wrist & $51 \cdot 7 \pm 3.9$ & $46-57$ \\
Terminal delay & $3 \cdot 75 \pm 0.5$ & $3 \cdot 5-4.5$ \\
Lateral popliteal & & \\
Kneo-ankle & $47 \pm 7.9$ & $30-54$ \\
Terminal delay & $6.8 \pm 1 \cdot 4$ & $5 \cdot 5-9.5$ \\
\hline
\end{tabular}

Maximum motor conduction velocities expressed in $\mathrm{m} / \mathrm{sec}$.

Terminal delay measured in msec.

most severe motor nerve involvement on clinical examination. Case 5, who on clinical examination had signs of motor nerve disturbance in the lower limbs only, gave the lowest recorded maximum conduction velocity in the kneeankle segment $(30 \mathrm{~m} / \mathrm{sec})$, together with an abnormally long terminal delay of $9.5 \mathrm{msec}$ in the anterior tibial nerve. Both patients had striking abnormalities of sensory nerve function; cutaneous sensory nerve potentials were unrecordable in both cases and the latency of the H-reflex was much prolonged (34 $\mathrm{msec}$ and $40.5 \mathrm{msec}$ ).

The mean values for the maximum conduction velocities for patients without neuropathy (group II) are given in Tables 3 and 4.

These mean values for both subgroups of alcoholics without neuropathy are within acceptable normal limits, although certain patients are exceptional. In the subgroup under 50 years of age, two patients showed reduced maximum conduction velocities in the knee-ankle segment

TABLE 3

MAXIMUM MOTOR CONDUCTION VELOCITIES IN ALCOHOLIC PATIENTS WITHOUT NEUROPATHY (GROUP II $<50$ YEARS)

\begin{tabular}{lrc}
\hline Nerve & Mean $( \pm$ one $S D)$ & Range \\
\hline Median & & \\
$\quad$ Axilla-elbow & $62 \cdot 9 \pm 7 \cdot 8$ & $48-75$ \\
Elbow-wrist & $56 \cdot 1 \pm 4 \cdot 5$ & $48-62$ \\
Terminal delay & $3 \cdot 8 \pm 0 \cdot 7$ & $2 \cdot 75-5 \cdot 3$ \\
Lateral popliteal & & \\
Knee-ankle & $48 \cdot 1 \pm 7 \cdot 2$ & $33-58$ \\
Terminal delay & $6 \cdot 9 \pm 1 \cdot 7$ & $4 \cdot 25-11$ \\
\hline
\end{tabular}

Maximum motor conduction velocities expressed in $\mathrm{m} / \mathrm{sec}$.

Terminal delay measured in msec.
TABLE 4

MAXIMUM MOTOR CONDUCTION VELOCITIES IN ALCOHOLIC PATIENTS WITHOUT NEUROPATHY (GROUP II $>50$ YEARS)

\begin{tabular}{lrc}
\hline Nerve & Mean $( \pm$ one $S D)$ & Range \\
\hline Median & $52 \cdot 3 \pm 9 \cdot 1$ & \\
$\quad$ Axilla-elbow & $53 \cdot 3 \pm 5 \cdot 8$ & $31-60$ \\
Elbow-wrist & $3 \cdot 7 \pm 0.4$ & $43-61$ \\
Terminal delay & & $3 \cdot 1-4 \cdot 3$ \\
& & \\
Lateral popliteal & $48 \pm 9 \cdot 3$ & $40-65$ \\
Knee-ankle & $5 \cdot 8 \pm 1 \cdot 5$ & $3 \cdot 5-7 \cdot 5$ \\
Terminal delay & & \\
\hline
\end{tabular}

Maximum motor conduction velocities expressed in $\mathrm{m} / \mathrm{sec}$. Terminal delay measured in msec.

of the lateral popliteal nerve, and prolonged terminal delay in the anterior tibial branch of this nerve $(39 \mathrm{~m} / \mathrm{sec}, 7.9 \mathrm{msec} ; 33 \mathrm{~m} / \mathrm{sec}$, $11 \mathrm{msec}$ respectively).

Similarly in the 51 to 65 years subgroup, one patient had abnormally low maximum conduction velocities in both segments of the median nerve (axilla-elbow segment $31 \mathrm{~m} / \mathrm{sec}$; elbowwrist $43 \mathrm{~m} / \mathrm{sec}$ ). These three patients also had notable electrophysiological abnormalities on examination of peripheral sensory nerves; the amplitude of the recorded sensory nerve potentials was reduced for all three and the latencies of the H-reflex and ankle jerk abnormally long.

MINIMUM MOTOR CONDUCTION VELOCITIES Displayed in Table 5 are the values for the maximum and minimum conduction velocities measured in the ulnar nerve of eight alcoholic patients drawn from group II, compared with those values determined for a group of eight control subjects. Two values for the minimum velocity are given in each instance. The first has been calculated as previously described; for the second value, $1 \mathrm{msec}$, to allow for the refractory period of the nerve, was deducted from the latency in each case. This second value was used to calculate the difference between the maximum and minimum conduction velocities. The mean of the differences between maximum and minimum conduction velocities was found for each group; for the alcoholic group the mean was $23.75 \mathrm{~m} / \mathrm{sec}$, and for the control group 13.63 $\mathrm{m} / \mathrm{sec}$. This discrepancy between the two groups is highly significant $(P<0.001)$, and indicates pathological change in the smaller calibre motor nerve fibres in the alcoholic patients. 
TABLE 5

ULNAR NERVE CONDUCTION VELOCITIES IN PATIENTS AND CONTROLS

\begin{tabular}{|c|c|c|c|c|c|c|c|c|c|}
\hline \multicolumn{5}{|c|}{ Patients } & \multicolumn{5}{|c|}{ Controls } \\
\hline $\begin{array}{c}\text { Age of } \\
\text { patient } \\
(y r)\end{array}$ & $\begin{array}{c}\text { Maximum } \\
\text { velocity } \\
(\mathrm{m} / \mathrm{sec} .)\end{array}$ & $\begin{array}{c}\text { Minimum } \\
\text { velocity } \\
(\mathrm{m} / \mathrm{sec} .)\end{array}$ & $\begin{array}{l}\text { Minimum } \\
\text { velocity } \\
\text { if I msec. } \\
\text { allowed for } \\
\text { refractory } \\
\text { period } \\
(\mathrm{m} / \mathrm{sec})\end{array}$ & Difference & $\begin{array}{c}\text { Age of } \\
\text { patient } \\
(y r)\end{array}$ & $\begin{array}{c}\text { Maximum } \\
\text { velocity } \\
(\mathrm{m} / \mathrm{sec} .)\end{array}$ & $\begin{array}{l}\text { Minimum } \\
\text { velocity } \\
(\mathrm{m} / \mathrm{sec} .)\end{array}$ & $\begin{array}{l}\text { Minimum } \\
\text { velocity } \\
\text { if } 1 \text { msec. } \\
\text { allowed for } \\
\text { refractory } \\
\text { period } \\
(\mathrm{m} / \mathrm{sec})\end{array}$ & Difference \\
\hline 27 & 49 & 22 & 24 & 25 & 34 & 54 & 30 & 34 & 20 \\
\hline 45 & 56 & 25 & 28 & 28 & 44 & 52 & 38 & 42 & 10 \\
\hline 42 & 60 & 33 & 37 & 23 & 47 & 49 & 33 & 38 & 11 \\
\hline 45 & 53 & 31 & 35 & 18 & 59 & 55 & 35 & 39 & 16 \\
\hline 43 & 54 & 27 & 30 & 24 & 37 & 53 & 27 & 31 & 22 \\
\hline 32 & 58 & 35 & 41 & 17 & 26 & 55 & 37 & 41 & 14 \\
\hline 29 & 56 & 26 & 29 & 27 & 56 & 49 & 34 & 38 & 11 \\
\hline 45 & 63 & 31 & 35 & 28 & 40 & 54 & 34 & 38 & 16 \\
\hline
\end{tabular}

Patients: mean of the difference between maximum and minimum conduction velocities $(1 \mathrm{msec}$ allowed for $\mathrm{RP})=23 \cdot 75 \mathrm{~m} / \mathrm{sec}$. SD 3.99 . Controls: mean of the difference between maximum and minimum conduction velocities $(1 \mathrm{msec}$ allowed for $\mathrm{RP})=13.63 \mathrm{~m} / \mathrm{sec}$. SD 4.09 . $P<0.001$ (Mann-Whitney test of significance).

TABLE 6

CUTANEOUS SENSORY NERVE POTENTIALS IN PATIENTS AND CONTROLS

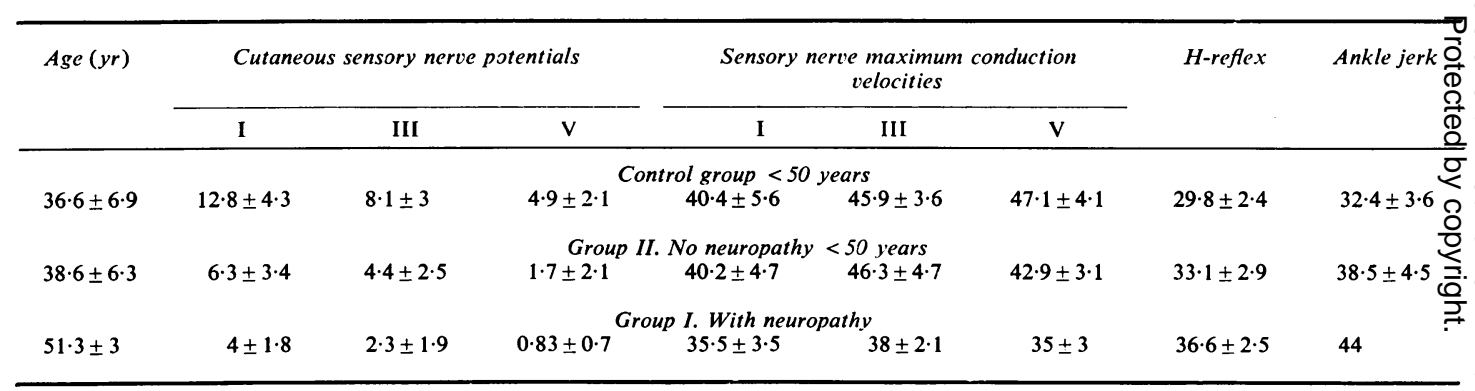

All mean values for amplitude of sensory nerve potentials expressed in microvolts \pm one S.D.

All sensory nerve maximum conduction velocities expressed in metres per second \pm one S.D.

Latencies of H-reflex and ankle jerk measured in msecs \pm one S.D.

CUTANEOUS SENSORY NERVE POTENTIALS, H-REFLEX, AND ANKLE JERK LATENCIES The mean values for the amplitude of the cutaneous sensory nerve potentials and their maximum velocities for patients in group I, group II patients aged less than 50 years (17 in number), and control subjects under 50 years (11 in number) are summarized in Table 6. Although these measurements were made on all five digits, results are given for digits 1,3 , and 5 only, as these are entirely representative of the overall findings. These measurements made on group II patients and control subjects over 50 years have not been included because it was felt that the numbers in each group were too few for effective comparison to be made. Table 6 also includes the latencies of the H-reflex and ankle jerks for each group.
As is evident, the control group (mean age $36.6 \pm 6.9$ years) is comparable in age with that subgroup of alcoholics without neuropathy aged less than 50 years (mean age $38 \cdot 6 \pm 6 \cdot 3$ years). The mean values for the sensory nerve maximum conduction velocities in both these groups are very similar and are within normal limits. There is, however, a small reduction of the maximum sensory nerve velocities in those patients who also showed signs of neuropathy.

Alcoholic patients in group I and group II show marked reductions in the mean values of the amplitude of the cutaneous sensory nerve potentials compared with the normal group. Also, in the group of normal subjects, sensory $\mathrm{c}$ potentials were in all cases elicited without difficulty; in the group of alcoholics without 
neuropathy, one patient had no recordable sensory nerve potentials; three other patients in this group had no recordable sensory potentials in at least two out of five digits.

The average latency of the $\mathrm{H}$-wave for the normal group was $29.8 \mathrm{msec}$, and that of the ankle jerk, $32.4 \mathrm{msec}$. The average latency of both these reflexes was prolonged in those alcoholics without neuropathy and increasingly lengthened in those alcoholic patients with neuropathy. Only one patient in group I had an ankle jerk which was unimpaired; the latency of this was markedly lengthened (44 msec).

\section{DISCUSSION}

Our findings indicate that, in both alcoholics with clinical evidence of polyneuropathy and in those who as yet showed no signs of peripheral nerve disease, maximum motor conduction velocities were within normal limits for the majority of our patients. Only five patients, out of a total of 30 studied, showed lowered conduction velocities in certain segments of the peripheral nerves examined. Our results, therefore, differ from those of some workers (Jurko et al., 1964; Mawdsley and Mayer, 1965; Bergamini et al., 1965; Wanamaker and Skillman, 1966), who found a small reduction in maximum conduction velocities in a high proportion of the alcoholics they examined, but are compatible with the findings of others (Perfetti et al., 1964; Juul-Jensen and Mayer, 1966; Vacek et al., 1969).

Estimation of minimum conduction velocity in the ulnar nerve of eight alcoholic patients without neuropathy revealed impaired rates of conduction in the smaller calibre motor nerve fibres as compared with a similar group of healthy control subjects. Perfetti et al. (1967) demonstrated similar involvement of the finer motor nerve fibres in alcoholic patients, most of whom however had clinical evidence of polyneuropathy. It seems, therefore, that damage to finer motor nerve fibres is detectable before clinical symptoms and signs of nerve disorder appear.

We have found a marked reduction in amplitude of the cutaneous sensory nerve potentials in alcoholics, with a small reduction of the maximum sensory nerve velocities in those patients who also showed clinical signs of neuropathy. We would, therefore, agree with the observation of Bergamini et al. (1965) that sensory nerve fibres are more severely affected than motor fibres. This reduction in amplitude of the sensory potentials is most probably due to actual loss of distal sensory nerve fibres, and as the maximum velocities in the digital nerves remain unaffected in alcoholics without neuropathy, the larger sensory nerve fibres must undergo Wallerian degeneration at this stage.

The elegant work of Buchthal and Rosenfalck (1966) on the recovery of sensory nerves after local anaesthesia, showed that normal sensory thresholds of touch and two-point discrimination were reached when the sensory action potentials had attained just $40 \%$ of their preanaesthetic amplitude. Their findings help to explain why all modalities of sensation were preserved in the majority of our patients, although sensory action potentials were reduced by as much as $50 \%$ or more from normal levels.

Prolongation of the latencies of the H-reflex and the ankle jerk occurred in both alcoholics with and without neuropathy and may be the result of a number of processes. As function of the large efferent fibres was unimpaired, involvement of the large afferent (Ia) fibres which mediate the H-reflex may be assumed. The delayed latency of the ankle jerk could be the result of either involvement of afferent fibres or affection of the finer motor nerve fibres which supply the muscle spindles, thereby rendering them less sensitive to activation by stretching.

Mawdsley and Mayer have speculated on the nature of the underlying pathological process in alcoholic peripheral nerve disease. They claimed that the small reductions in maximum conduction velocities in both motor and sensory nerves, which they were able to demonstrate in their patients, were indicative of segmental demyelination being the significant pathological process. Our findings strongly suggest that, as far as the terminal portions of the sensory nerve fibres are concerned, axonal degeneration appears to be the main pathological event. The detailed histological study of Coërs and Hildebrand (1965) confirms this view; in addition to early evidence of motor end-plate abnormalities, they found distal degeneration and increased collateral ramification of motor nerve fibres to be present, both in alcoholic patients with minimal or no neuropathy. The normal terminal delays we have found in our patients indicate that, although end-plate abnormalities may exist, they do not interfere with function at nerve endings. 
It is possible, however, that differing pathological changes may take place along the course of a peripheral nerve, and indeed that sensory and motor nerve fibres may show dissimilar pathological responses to this particular biochemical insult. Segmental demyelination may therefore occur in large sensory fibres causing prolonged $\mathrm{H}$-reflex latencies, but leave, at that stage anyhow, the large motor fibres unscathed.

The aetiology of alcoholic polyneuropathy remains uncertain. Shattuck (1928) first suggested its nutritional origin, indicating that it was comparable with beriberi. Strauss (1935) produced evidence against the direct neurotoxic effect of alcohol and concluded that dietary deficiencies were important in the development of alcoholic polyneuropathy. Denny-Brown (1958) drew attention to the differences between the clinical findings in beriberi and in alcoholic neuropathy: the former is characterized by symmetrical foot and wrist drop, associated with muscle tenderness, and only a mild disturbance of general sensation over characteristic areas; the latter he described as a chronic sensory neuropathy with marked disturbance of pain sensation and often prominent burning paraesthesiae in the feet. The electrophysiological abnormalities we have demonstrated reflect well the clinical picture of alcoholic neuropathy which he outlined.

Evidence of thiamine deficiency was present in four out of 13 of our patients and deficiency of this vitamin may therefore have contributed to the peripheral nerve damage we detected. It is clear, however, that we cannot exclude the part played by deficiencies of other essential nutrients in the development of alcoholic peripheral nerve disease.

Warm thanks are expressed to: Dr. F. J. J. Letemendia for his permission to study his patients; Mr. G. Higgins for his biochemical help; Miss Gloria Woodward and Miss Sylvia Davis for their electrophysiological assistance; Miss Diana Staples for statistical advice; Mr. J. Staněk for help with translation.

This research was carried out with the aid of a grant from the Medical Council on Alcoholism, to whom our thanks are due.

\section{REFERENCES}

Bergamini, L., Gandiglio, G., Fra, L., Bergamasco, B., ؟ Bram, S., and Mombelli, A. M. (1965). Alterazioni della conduzione nervosa sensitiva e motoria in alcoolisti $\underset{7}{\overrightarrow{7}}$ cronici privi di segni clinici di neuropatia periferica. Rivista di Patologia Nervosae Mentale, 86, 31-49.

Buchthal, F., and Rosenfalck, A. (1966). Evoked action $\mathscr{\mathcal { S }}$ potentials and conduction velocity in human sensory $\bar{\square}$ nerves. Brain Research, v-viii, 1-122.

Coërs, C., and Hildebrand, J. (1965). Latent neuropathy in diabetes and alcoholism. Electromyographic and histological study. Neurology (Minneap.), 15, 19-38.

Denny-Brown, D. (1958). Special problems concerning ه beriberi. A. The neurological aspects of thiamine deficiency. of In Nutritional Disease. Proceedings of a Conference on $\vec{O}$ Beriberi, Endemic Goiter and Hypovitaminosis A, Princeton, N.J., 1958, pp. 35-39. Edited by T. D. Kinney and R. H. Follis, Jr. Federation Proceedings, 17, Suppl. No. 2.

Hopf, H. C. (1962). Untersuchungen über die Unterschiede in der Leitgeschwindigkeit motorischer Nervenfasern beim Menschen. Deutsche Zeitschrift für Nervenheilkunde, 183, 579-588.

Hopf, H. C. (1963). Electromyographic study on so-calle mononeuritis. Archives of Neurology, 9, 307-312.

Jurko, M. F., Currier, R. D., and Foshee, D. P. (1964) N Peripheral nerve changes in chronic alcoholics: a study conduction velocity in motor nerves. Journal of Nervo and Mental Disease, 139, 488-490.

Juul-Jensen, P., and Mayer, R. F. (1966). Threshold stimula্̧ك tion for nerve conduction studies in man. Archives of Neurology, 15, 410-419.

Mawdsley, C., and Mayer, R. F. (1965). Nerve conduction alcoholic polyneuropathy. Brain, 88, 335-356.

Norris, A. H., Shock, N. W., and Wagman, I. H. (1953). Age changes in the maximum conduction velocity of motor fibres of human ulnar nerves. Journal of Applied Physiology, 5, 589-593.

Perfetti, C. C., Milone, F. F., and Pacchiani, A. (1967). Studio dei valori di dispersione della velocità di conduzione (VDC) delle fibre motorie negli alcoolisti. Rivista di $\stackrel{\triangleright}{\circledR}$ Neurologia, 37, 453-461.

Shattuck, G. C. (1928). The relation of beri-beri to polyneuritis from other causes. American Journal of Tropical Medicine, 8, 539-543.

Strauss, M. B. (1935). The aetiology of 'alcoholic' polyneuritis. American Journal of the Medical Sciences, 189, 378-382.

Vacek, J., Štika, L., Grófová, E., and Warman, C. (1969). Periferní Neuron u Alkoholismu. Časopis Lékarú Českých, 108, 331-336.

Wanamaker, W. M., and Skillman, T. G. (1966). Motor nerve conduction in alcoholics. Quarterly Journal of Studies on Alcohol, 27, 16-22. 